\title{
A Case Study of Energy Deposition and Absorption by Magnetic Cloud Electrons and Protons over the High Latitude Stations: Effects on the Mesosphere and Lower Thermosphere
}

\author{
Olakunle Ogunjobi *, Venkataraman Sivakumar, and Nkanyiso Mbatha \\ School of Chemistry and Physics, University of KwaZulu-Natal, Durban, South Africa
}

Received 15 March 2013, accepted 14 October 2013

\begin{abstract}
Several possible characteristics of magnetic clouds (MCs) have been discussed in the literature, but none appears to explain all the effects from accumulated observations. MC characteristics range from low proton temperature and plasma beta, to high magnetic field magnitude, to smooth rotation in the direction of the magnetic field thus resulting in strong geomagnetic disturbances. Varied instrumentation which is located not only in SANAE IV, Antarctica, but also at Halley, a same radial distance $(L \sim 4)$ in the southern hemisphere and in the vicinity of a conjugate location in northern hemisphere provide an opportunity to test theories applied to high latitude heating rates on the arrival of MC. The Halley riometer is used to monitor coincidences of absorption with the arrival of MC which was observed on 8 November 2004. Using the Monte Carlo Energy Transport Model (MCETM), the corresponding altitude of electron and proton energy distribution indicates the importance of MC triggered geomagnetic storms on mesosphere dynamics.
\end{abstract}

Key words: Magnetic Cloud, Precipitation, MLT region, Absorption, Energy deposition, $L$ shell

Citation: Ogunjobi, O., V. Sivakumar, and N. Mbatha, 2014: A case study of energy deposition and absorption by magnetic cloud electrons and protons over the high latitude stations: Effects on the mesosphere and lower thermosphere. Terr. Atmos. Ocean. Sci., 25, 219-232, doi: 10.3319/TAO.2013.10.14.01(AA)

\section{INTRODUCTION}

Solar wind is responsible for fueling magnetospheric storms, forming the Earth's magnetosphere. Energetic particles and momentum from the solar wind are consequently conveyed in form of energy to the terrestrial atmosphere via particle precipitation or as electromagnetic radiation. The region of the mesosphere $(50-100 \mathrm{~km})$ and lower thermosphere $(100-180 \mathrm{~km})$ is not fully understood when considering the overall energy budget in the Earth's atmosphere. The complication in understanding the energy budget ranges from the hemispherical differences to the large number of external and internal processes that are able to heat the atmosphere and as well cool it, depending on the specific effective conditions present (Roble 1995). However, for several decades, one of the controversial problems in solar-terrestrial physics has been the impact of solar activities on atmospheric energetics and dynamics (Georgieva et al. 2005). Several geophysical parameters are often used

\footnotetext{
* Corresponding author

E-mail: olakunle.ukzn@gmail.com
}

to gauge the impact of solar-terrestrial disturbances on the Earth's atmosphere (Zhang et al. 2006). Despite the present coordinated solar and geophysical parameters and meterological indices, it has been noted that the two solar hemispheres affect the Earth in a number of ways.

A major source of enhanced ionisation in the ionosphere is as a result of precipitating energetic particles depositing their energy in the upper atmosphere during geomagnetic disturbances, e.g., Estep et al. (1999). Particles, especially, electrons which usually have small mass, can be scattered through very large angles when they collide with neutrals in the atmosphere. If the resulting deviations decrease the pitch angle, it will backscatter and penetrate more on the other end of its bounce trajectory. On the other hand, if the deviations increase the pitch angle, it can lead to further penetration into the atmosphere causing loss of more energy by collisions. The presence of avalanche particles triggered by precipitation will increase atmospheric energy and ultimately influence the composition of the atmosphere through ionisation, dissociation and excitation. Also, the helicity of the magnetic structure in the plasma of solar wind flow 
governed by the electric field, together with the presence of resulting temperature gradients change neutral winds. Such perturbation induces chemical heating rates and infrared cooling. Precipitating particles produce forms of odd nitrogen $\left(\mathrm{NO}_{\mathrm{x}}\right)$ and odd Hydrogen $\left(\mathrm{HO}_{\mathrm{x}}\right)($ Swider and Kenesha 1973; Rusch et al. 1981; Solomon et al. 1981; Sætre et al. 2004; Rodger et al. 2010b; Kang et al. 2012) which undergo a series of chemical reactions. Although minor gases, if they enter the uppermost layer of the stratosphere and troposphere, they contribute to the overall processes that catalytically deplete ozone (Grenfell et al. 2006) and partly affect the radiation budget of the polar atmosphere.

It has been noted recently that the helicity of magnetic structure is the most prominent feature of solar activity which determines the effectiveness of geomagnetic disturbances in both the southern and northern hemispheres (Antonucci et al. 1990). Scientific understanding of this feature requires an event based study, in particular, interplanetary coronal mass ejections (ICMEs) events. Burlaga et al. (1982) had earlier found that the strongest geomagnetic disturbances are predominant when the Earth encountered magnetic clouds (MCs) associated with ICMEs. A MC is a transient ejection in the solar wind defined by relatively strong fields, a smooth rotation of the magnetic field direction over about 0.25 and $1 \mathrm{AU}$, a low proton temperature and a low plasma pressure to magnetic pressure ratio (Burlaga 1988). MC is further characterised by Lepping et al. (1990) as the region between the leading half of the z-component of southward interplanetary magnetic field (IMF-Bz) and the trailing half which contains a strong northward peak, or vice versa, with an accompanying large density enhancement which strongly compressed the magnetosphere. These interplanetary properties have been found to be triggers of geomagnetic storms (Lepping et al. 1997).

The interactions of the precipitating energetic particles, associated with the storms, with increasingly denser atmospheric neutrals, such as hydrogen and nitrogen, in the MLT altitude ranges can produce the emissions which characterise the auroras. The difference between the normal and MC induced auroras has been investigated in the Northern high latitude by Hviuzova and Leontyev $(1997,2001)$. Based on the aurora observation data at the Loparskaya Observatory during 1970 - 1985, the yearly means of the of auroral intensity ratio were obtained. They showed that during MCaurora there was an enhanced mean ratio between the red

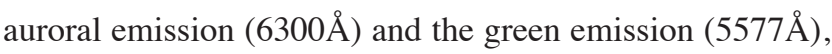
with the spectrum of precipitating electrons being shifted to the higher energies during the MC aurora type. This implies that the intensity and efficiency of energy deposition by MC are strongly altitude dependent. Similarly, the work of Sivjee and Shen (1997) examined the auroral emissions during the solar MC on October 18, 1995. Using continuous spectroscopic measurements, it was shown that there is a difference between the normal auroras and the MC induced auroras. Despite the possible ability of compressed MCs to cause many large geomagnetic storms (Wang et al. 2003), there has been little significant attention as to its effects on the MLT energy budget. It should be noted, Georgieva et al. (2005) showed the probable impact of MC on the middle atmosphere based on the geo-effectiveness of the $\mathrm{MC}$ and phases of the quasibiennial (QBO) oscillation of equatorial stratospheric winds. The general effects were found to be strongest for south-north oriented clouds in the QBO easterly phase. However, their statistical study, which was based on direct measurement, excludes the link between MC to energetic particles precipitating onto the atmosphere.

Based on the aforementioned studies, therefore, there is a need to estimate the energy deposition based upon model calculations with measurements and careful consideration of hemispherical differences to determine the influence on an energy balance on arrival of MC in the high latitude MLT region. In this paper, we investigate MLT responses to a fortuitous MC-driven geomagnetic storm which occurred on 8 November 2004 using ground and satellite based measurements from SANAE IV $\left(71.7^{\circ} \mathrm{S}, 2.9^{\circ} \mathrm{W}, L=4.3\right)$ and a nearby station, Halley $\left(75.52^{\circ} \mathrm{S}, 26.63^{\circ} \mathrm{W}, L=4.2\right)$ in Antarctica and also from the nearest vicinity of their conjugate magnetic footprint in the Northern hemisphere. This paper is organised as follows; we describe the data used in section 2 . section 3 presents the various geophysical properties of MC and the effects from precipitating particle measurements; we present estimated energy deposition using the Monte Carlo energy transport method. Section 4 summarises the obtained results and conclusions.

\section{DATA AND METHOD OF ANALYSIS}

\subsection{Observations}

\subsubsection{Geophysical Parameters}

The geophysical parameters for this event were obtained from the space physics research facility in the OmniWeb database. The data set was created at the National Space Science Data Center, http://omniweb.gsfc.nasa.gov, by interspersing, after cross-normalizing, field and plasma data from each of several spacecrafts that contribute measurements (King and Papitashvili 2005). Therefore, the database provides multi-source measurements of near-Earth solar wind, magnetic field and plasma parameters from different instruments. The solar activity indices (King and Papitashvili 2005), included in the database served as a proxy for the state of the ring current and magnetospheric convection. From different parameters available from the database, only those relevant to characterising the $\mathrm{MC}$ were obtained as presented in section 3.1.

\subsubsection{The Imaging Riometer Absorption Data}

To study the reaction of MCs with the atmosphere over 
the region of interest, we used the imaging riometer data (Hargreaves 1969; Browne et al. 1995; Wilson and Stoker 2002). The riometer data employed in this study was obtained from two locations, Halley in the Southern Hemisphere and stations belonging to the Finnish chain which is at the vicinity of the Halley magnetic conjugate in the Northern Hemisphere. One other aim of this work is to build a futurology over SANAE IV. Halley riometer techniques (Hargreaves 1969) are similar to that from SANAE IV (Wilson and Stoker 2002) but no data was available at SANAE IV during the event. It should be noted that the ionospheric status in Halley will be a true representative of absorption above SANAE IV due to the proximity of both stations along the same magnetic field line. The Earth's encounter with MC will modify the magnetic field significantly. Under adiabatic changes to the geomagnetic field $L$ is a conserved quantity (Roederer 1970). In a dipole magnetic field, $L$, is the distance from the centre of the Earth to the equatorial crossing point of a given field line. The McIlwain $L$ shell used in this study is calculated using the International Geomagnetic Reference Field (IGRF) model from http://ngdc.noaa.gov. It is expected that for any simultaneous precipitation, where particles are precipitated over a wide region, it would be detected at both stations simultaneously. For this reason the conjugate points of all the riometer data used are shown. Figure 1 shows that Halley and the Finnish riometer chains are on roughly the same $L$-shell, but are separated by about 4 hours of magnetic local time. The field line from Halley and SANAE IV intersects at Oulu, a location at close proximity to Rovalemi in Northern Hemisphere. The so called 'Wave-particle' interactions on a given field line may lead to precipitation at both foot-points of the field line. Therefore, the effect at the conjugate hemisphere is more true for
Oulu and Rovalemi, which is at a roughly same $L$-value with SANAE IV and Halley. The locations of the Finnish chain of riometer stations and their $L$-values are tabulated in Table 1. A riometer responds to the integrated absorption of cosmic ray noise through the ionosphere (Clilverd et al. 2010) where the particle motion is collision dominated. The riometers are widebeam, typically $30 \mathrm{MHz}$ and sensitive to any incident particle population capable of reaching the ionosphere in the range of $70-100 \mathrm{~km}$ (that is, D-region).

The amount of the background cosmic radio noise disrupting the ionosphere is known to be constant for a particular location and at a given time of the day. In order to identify extraordinary absorption, a reference Quiet Day Curve (QDC) is an important parameter to be considered. Any deviations from this expected value must be due to absorption in the ionosphere as used in this study. An absorption due to such an event was quantified by calculations of an electron number density.

\subsubsection{Precipitation}

The absorption was expected to be as a result of precipitating particles on 8 November 2004. So, we used electron and proton data from NOAA/POES (National Oceanic and Atmospheric Administration Polar Orbiting Environmental Satellites). During this event, three satellites, NOAA 15, 16 and 17 were orbiting the Earth in a polar-orbiting, Sunsynchronous, and low-altitude $(850 \mathrm{~km})$ pass with a period of about 100 minutes. Each satellite, has on-board the Medium Energy Proton and Electron Detector (MEPED) and Total Energy Detector (TED) that monitor the intensities of charged particle radiation at higher energies (Rodger et al. 2010a). The MEPED on each satellite provides directional

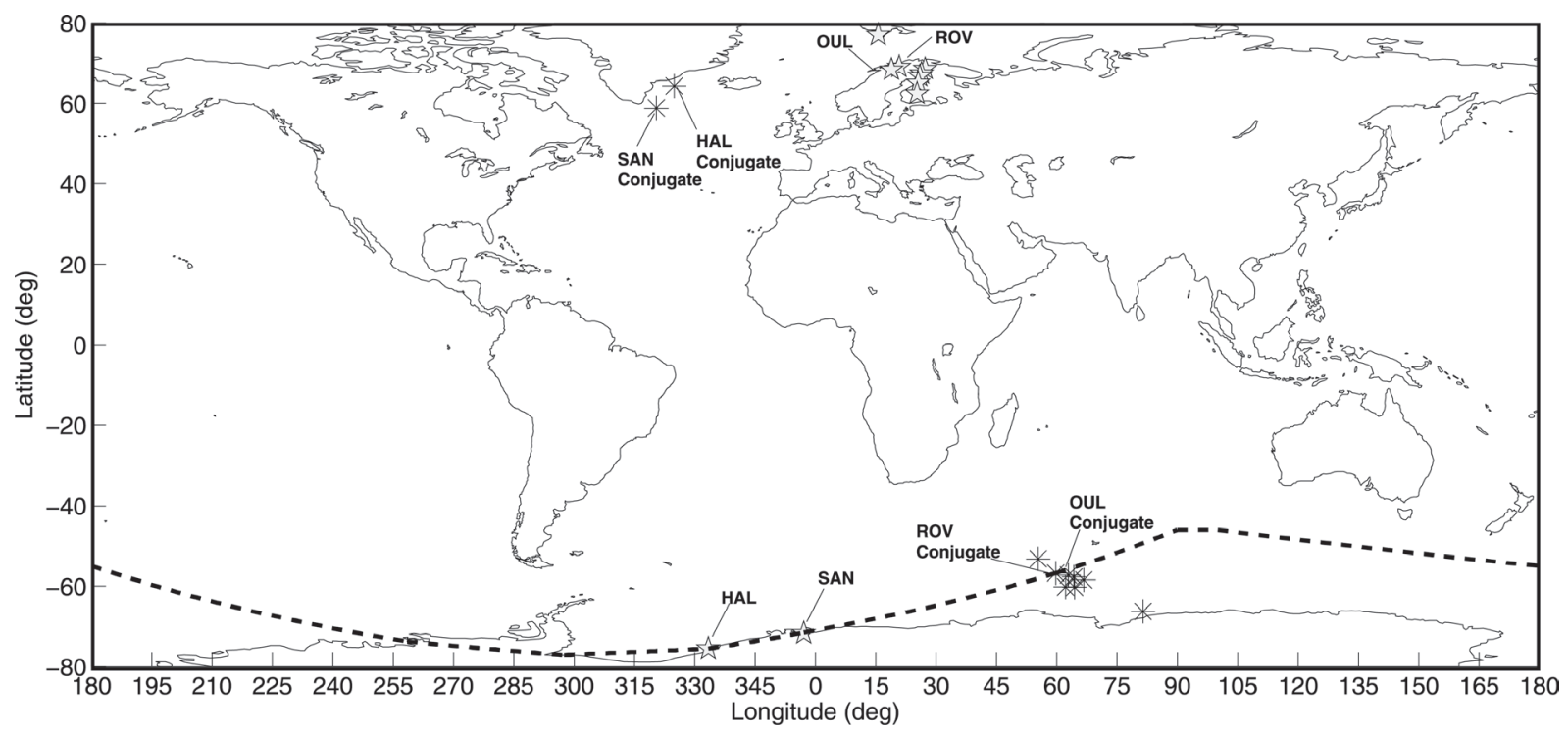

Fig. 1. Map showing locations of Halley's riometer, SANAE IV, the Finnish riometer chain with a star symbol and their conjugate points in pentagrams. Halley's $L$-shell is plotted as a dashed black curve. 
Table 1. Locations of the riometer data used.

\begin{tabular}{cccc}
\hline Station Name & Station Code & Geographic coordinates & $L$-value \\
\hline SANAE IV & SAN & $71.68^{\circ} \mathrm{S}, 2.85^{\circ} \mathrm{W}$ & 4.32 \\
Halley & HAL & $75.52^{\circ} \mathrm{S}, 26.63^{\circ} \mathrm{W}$ & 4.2 \\
Hornsund & HOR & $77.00^{\circ} \mathrm{N}, 15.60^{\circ} \mathrm{E}$ & 13.2 \\
Kilpisjärvi & IRIS & $69.05^{\circ} \mathrm{N}, 20.79^{\circ} \mathrm{E}$ & 6.0 \\
Abisko & ABI & $68.40^{\circ} \mathrm{N}, 18.90^{\circ} \mathrm{E}$ & 5.7 \\
Ivalo & IVA & $68.55^{\circ} \mathrm{N}, 27.28^{\circ} \mathrm{E}$ & 5.6 \\
Sodankylä & SOD & $67.42^{\circ} \mathrm{N}, 26.39^{\circ} \mathrm{E}$ & 5.2 \\
$*$ Rovanlemi & ROV & $66.78^{\circ} \mathrm{N}, 25.94^{\circ} \mathrm{E}$ & 4.9 \\
$*$ Oulu & OUL & $65.05^{\circ} \mathrm{N}, 25.54^{\circ} \mathrm{E}$ & 4.4 \\
Jyväskylä & JYV & $62.42^{\circ} \mathrm{N}, 25.28^{\circ} \mathrm{E}$ & 3.7 \\
\hline
\end{tabular}

Note: * ROV and OUL are the closest conjugate vicinity of SANAE IV and Halley.

$\left(0^{\circ}\right.$ telescopes for precipitating and $90^{\circ}$ for trapped) measurements of protons and energetic electrons. For this study, data from the $0^{\circ}$ telescope was selected only when it measured protons and electrons inside the loss cone. Similarly, TED monitors proton and electron fluxes. Four detectors (two electrons and two proton detectors) are mounted in two groups, where one group is viewing radially outward from the Earth and the other group viewing at $30^{\circ}$. Each group has a proton and an electron detector. At aurora altitudes the first group, looks approximately along the field line referred to as the vertical detector. In this study, we used fluxes from the TED vertical detector. Also, the POES measurements were ordered by parameter $L$. The MEPED measurements of energetic electrons have been found to be proton contamination (Rodger et al. 2010a). This study applies correction to remove protons from the precipitating electron data. For this corrective purpose, data from $0^{\circ}$ telescope was selected only when it measure electrons inside the loss cone. The fidelity of reducing proton contamination, to provide clean measurements of precipitating electrons, was obtained from Lam et al. (2010) who suggested a first order correction,

$\alpha+15^{\circ}<\alpha_{L C}$

where $\alpha$ is the local particle pitch angle at the satellite, $\alpha_{L C}$ is the edge of the lost cone, while the telescope opening angle is $15^{\circ}$. Assuming conservation of the first adiabatic invariant, the local pitch angle at the satellite, equivalent to the edge of the loss cone was determined by:

$\alpha_{L C}=\int \frac{B_{s a t}}{B_{120}}$

Both the ambient magnetic field at the spacecraft $B_{\text {sat }}$ and the ambient magnetic field at the foot of the field line which intersects $\sim 120 \mathrm{~km}$ above the Earth are obtained from IGRF model.

\subsection{Model Calculations}

\subsubsection{Energy Deposition}

Based on Berger et al. (1970), the energy deposition by the energetic particles is calculated using the Monte Carlo Energy Transport model herein refer to as MCETM:

$s_{m b}=\frac{z_{m}\left(h_{b}\right)-z_{m n}}{\cos \theta_{n}}$

where, $z_{m}\left(h_{b}\right)=\int_{h}^{h_{0}} D\left(h_{b}{ }^{\prime}\right) d h^{\prime}$ is the atmospheric depth used as an input for the model with $D\left(h_{b}{ }^{\prime}\right)$ as the density supposing the electron passes through a particular 'scoring boundary' $h_{b}$ between the $n^{\prime}$ th and $n+1^{\prime}$ st collisions, and $z_{m}\left(h_{b}\right)$ being the mass thickness at each corresponding height. The distance, $s_{m}$, traveled by electrons within the boundary $b$ was given as:

$s_{m}=\int_{E_{n+1}}^{E_{n}} \frac{d E}{L(E)}=r_{0}\left(E_{n}\right)-r_{0}\left(E_{n+1}\right)$

which we obtained by interpolating the atmospheric mean range $r_{0}$ against acquired electrons' energy $E$ using stopping power $L$. The pathlength from the $n^{\prime}$ th collision point to the boundary results to $s_{m b}$ as given in the first equation.

Berger et al. (1970) noted the applicability of this program to problems which were actually observed atmospheric phenomena and those predicted by the simplified calculations. In this case, rather than theoretical assumption of characteristic energy, we first combined the electron $(>30,>100$, and 
$>300 \mathrm{keV}$ ) energies from MEPED detector into an energy range of $30-100$ and $100-300 \mathrm{keV}$, these integral fluxes are then combined with those retrieved from TED in the range of $2116-3075$ and $6503-9167 \mathrm{eV}$ to obtain differential fluxes. That is, the four differential energy channels are fitted into a double exponential spectrum:

$j(E)=A_{1} \cdot e^{-\frac{E}{E_{1}}}+A_{2} \cdot e^{-\frac{E}{E_{2}}}$

The characteristic energies, $E_{1}$ and $E_{2}$, and the factors $A_{1}$ and $A_{2}$ are then determined. We found a very high energy spectrum associated with this event with characteristic energies between 3 and $135 \mathrm{keV}$. At every pathlength, we obtained energy deposited at various heights of interest per time. Similar to Rees (1989), the energy expended by the primary precipitation for each ion-electron pair production is taken to be a value of $35 \mathrm{eV}$. Mæhlum (1973) provided a three part exponential technique useful for obtaining information about the deposition of proton energy as a function of altitude: $\frac{d E}{d z}=236 E^{-0.78}$, given that the energy loss, $\frac{d E}{d z}$, is in $\mathrm{M} \mathrm{eV} \mathrm{cm} \mathrm{g}^{-1}$ units. Using three part exponential function, we obtain the spectra used in MCTEM for proton energy deposition. Both electrons and protons were assumed to be vertically incident. In all, the aforementioned atmospheric composition and densities are estimated based on the Mass-Spectrometer-Incoherent-Scatter Extended model (MSISE-90) which is identical to the COSPAR International Reference Atmosphere-86 (CIRA-86).

\subsubsection{Electron Number Density}

Electron number density from an absorption of radio waves by the ionosphere was usually calculated using the Appleton-Hartree magnetoionic theory (Majumdar 1972). For the Halley riometer used in this study, the radio wave frequency $(30 \mathrm{MHz})$ was larger than both the component of the gyro-frequency vector in the direction of propagation, and the collision frequency. Using a classical equation (Hargreaves 1992) and approximation (Wang et al. 1994), the expression for the absorption $A(d B)$ was reduced to the following formula:

$A(d B)=\frac{4.58 \times 10^{-5} \pm \sqrt{b^{2}-4 a c}}{\omega^{2}} \int N_{e}(h) v(h) d s$

where $N_{e}(h)$ gives the electron number density at any height $h, v(h)$ which is $\sim \rho(h)$ (Hargreaves and Friedrich 2003) and obtained as the property of the atmosphere [i.e., proportional to pressure, $\rho(h)$ ], $\omega$ the radio wave angular frequency, and $d s$ the path element.

\subsection{The Event Characteristics}

A MC as one type of interplanetary ejecta can be identified by its definite geo effective signatures. Due to the important position of these signatures in solar terrestrial events, understanding the $\mathrm{MC}$ is valuable and helpful for the space weather research, especially for improving the prediction level of the occurrence of intense geomagnetic storms that can significantly affect the MLT energy budget. Measurements of geophysical parameters were then inspected from the OMNI data set for evidence of these signatures, including enhanced magnetic field strength, long and smooth rotation of field vector and low proton temperature (Burlaga et al. 1982; Burlaga 1988; Lepping et al. 1990). An enhanced magnetospheric convection resulting from the MC may be an indication that the solar wind energy gained access into the MLT region.

Figure 2 presents the geophysical properties of a MC event which occurred at about 3.4 UT on 8 November 2004 until 16.6 UT of the same day. Figure 2a is a strong magnetic field magnitude (peak value $40 \mathrm{nT}$ ) with low variance and organized rotation of the magnetic field direction $(\mathrm{y}-\mathrm{z})$ in geocentric solar magnetospheric (GSM) coordinate in Fig. 2b, and depressed proton number density in Fig. 2c. The solar wind speed is increased in Fig. 2d probably because this event is fast (a fast solar wind speed is defined as having speeds usually more than $500 \mathrm{~km} \mathrm{~s}^{-1}$ ). The helium to proton ratio in Fig. 2e is enhanced throughout the MC causing low pressure. The low ratio of plasma pressure to magnetic pressure is affirmed by the drop in dynamic pressure in Fig. $2 \mathrm{f}$ and plasma beta in Fig. $2 \mathrm{~g}$. The magnetospheric convection measurement, $\mathrm{Kp}$ index in OMNI format as presented in Fig. $2 \mathrm{~h}$ shows that the onset of event begins during enhanced magnetospheric activity indicating that the magnetosphere is immersed in high solar wind flow. It can be observed from this panel that there is a consistent pattern of magnetospheric response to the MC, as gauged by this index. Typical classifications of geomagnetic storms use the minimum of the Kp index to determine the size of the storm; by these classifications, this event is over 70 percent higher than the small geomagnetic storm.

The resultant increase in the activity during MC may cause the upper most layer of the magnetophere to move inward from its quiet-time median standoff distance. Such compression of the magnetopause from a stand-off distance will allow the gradual loss of energetic particles from the higher radial distances (that is, higher $L$-values). Depending upon the initial kinetic energy, particle of this magnetospheric origin can precipitate and be absorbed into different heights of the atmosphere.

\subsection{Particle Absorption and Precipitation}

Figure 3 shows hourly riometer absorption measurements.

\section{RESULTS AND ANALYSIS}


At the arrival of MC there is a rise in absorption in coincidence with the onset of high magnetospheric activities. The absorption peaks continue to reach a maximum on arrival of $\mathrm{MC}$ and drops slightly after impact. We continue to notice absorption 3 days after the event which is almost the same value with the peak seen on MC, indicating that the particle precipitation is fairly uniform over a large area. Generally, the different values in absorption seen after the MC indicate, however, the precipitation has some localised or multiple contributing processes. These observations can be seen in the vicinity of the northern conjugate measured by a Finnish chain of riometers as presented in Fig. 3b. It is also noted that the average absorption peaks follow the duration of an enhancement in the magnetosphere. The energy spectrum of the precipitating energetic particles varies from one event to another, as well as during an event. However, the criterion for MC occurrence is fulfilled throughout this period with the peaks in absorption at the main phase of the storms triggered by MC. Even so, we wish to ascertain if the changes or the high peak in absorption are actually due to changes in particle precipitation at the onset of this event. A way toward ascertaining this is to first quantify the resulting electron density from the ionospheric absorption.

Figure 4 shows the resultant electron densities using Eq. (6). In order to effectively exclude any other possible local and multiple contributing processes, we have centered the calculations on a single day of the MC. The main part of the MC produces ionisation around $90 \mathrm{~km}$ on arrival of MC at Earth until following day. The electron number density calculations show enhanced electron densities above $90 \mathrm{~km}$ on the impact of the MC which coincides with the rise in the $\mathrm{Kp}$ index. In these conditions, lower energy protons are also expected to reach the atmosphere. Comparing this model variations with riometer absorption in Fig. 3 shows that the two impulsive peaks on arrival of MC and a day following it coincide well with each other suggesting that there is indeed a precipitation of energetic electrons into the D-region ionosphere; although, there is some discrepancy in the early part

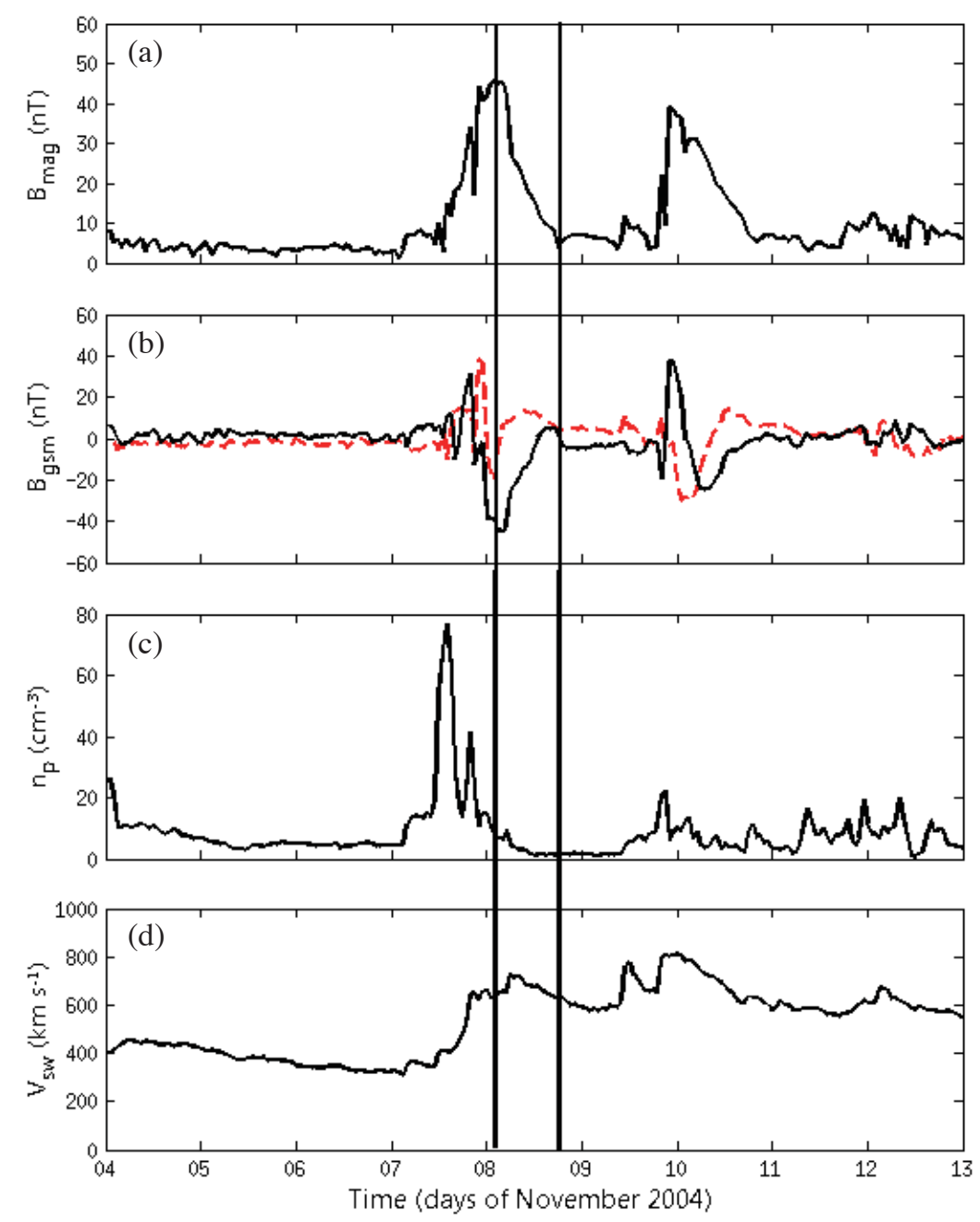

Fig. 2. Plots of properties of MC used: panels (a) show magnetic field magnitude, (b) IMF in GSM coordinate in z-component (black line) and y-component (red dashed line), (c) proton number density, (d) solar wind speed, (e) $\mathrm{n}_{\alpha} / \mathrm{n}_{\mathrm{p}}$, (f) dynamic pressure, (g) plasma beta, (h) Kp index in OMNI format. The vertical borderline indicates MC interval. 


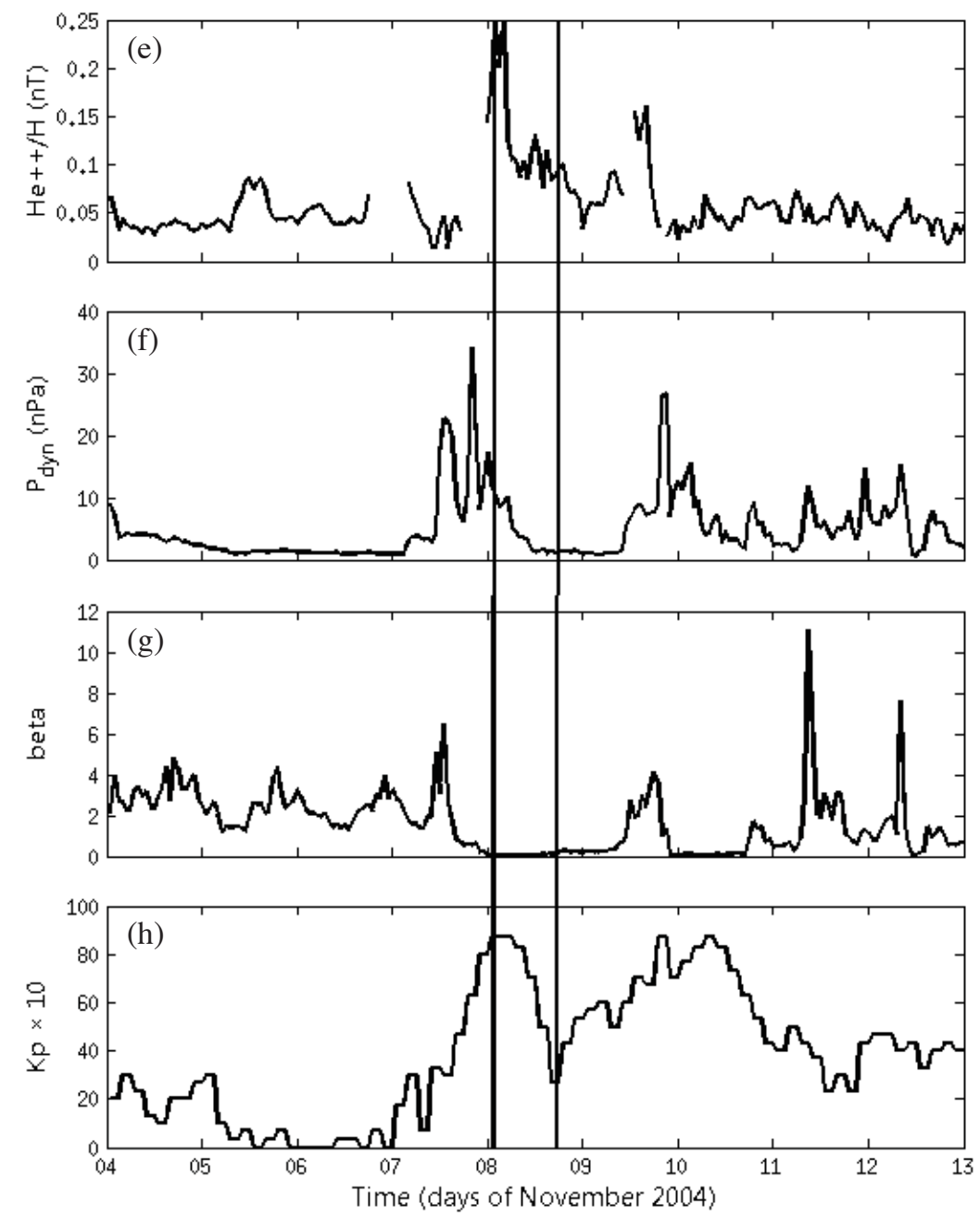

Fig. 2. (Continued)

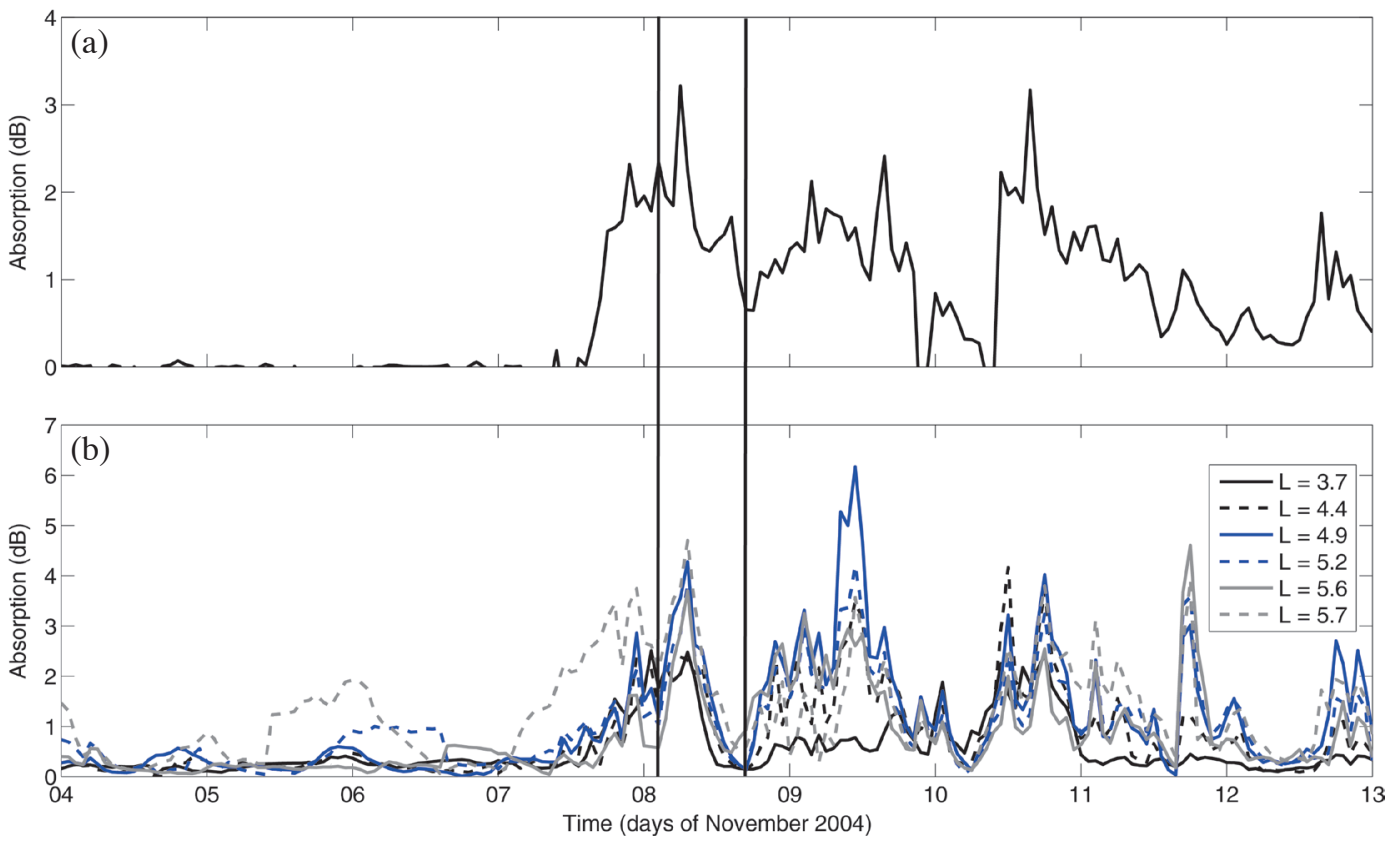

Fig. 3. Hourly riometers absorption during MC. (a) Indicates absorption from Halley and (b) Finnish chain of riometers. The format is same as in Fig. 2. 


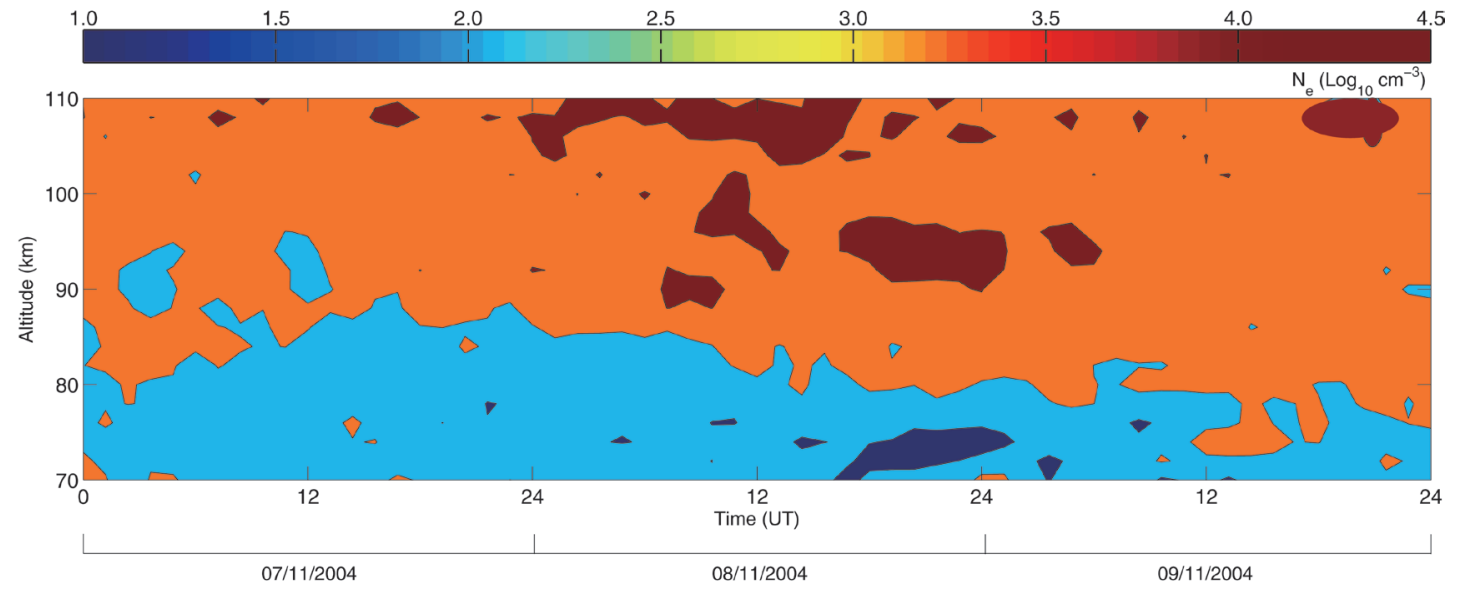

Fig. 4. Altitude-time-color map of modeled electron number density from absorption measurements.

(3:40 UT) of the event. This is likely to be as a result of the extremely low proton density at the start of the event, which causes less ionisation below $100 \mathrm{~km}$ altitude. On the other hand, the enhanced electron number densities above $100 \mathrm{~km}$ is due to background solar radiation in the E-region. For clarity, we checked the Solar flux proxy adjusted to 1 AU during the MC (not shown). The F10.7 index that measures the solar radio flux per unit frequency at a wavelength of $10.7 \mathrm{~cm}$ correlates well with Solar Extra Ultra Violet (EUV) emissions. A visual inspection indicated that the Solar flux proxy varied from 125 s.f.u. at the impact of MC to 140 s.f.u. a day after and later dropped to 90 s.f.u. The Halley and SANAE IV regions which lie entirely in the Southern Hemisphere's polar latitude receive relative high amount of solar EUV during summer. Previous studies, according to Sripathi (2012), have indicated that electron density varies linearly with solar flux. Another way to ascertain if the peaks in absorption are actually due to precipitation triggered by MC is to check the degree of precipitating particles at this time.

Using particle measurements from the $0^{\circ}$ detectors on the MEPED and TED instruments onboard NOAA 15, 16 and 17 , we obtained the precipitating particles over and near our regions of interest at several points in time. The particle measurement was projected down to about $100 \mathrm{~km}$ which is near the foot of the magnetic field line, and sort the measurement in a McIlwain $L$ shell of $\pm 0.02 L$ around Halley ( $L=4.2)$, SANAE IV $(L=4.3)$ and at the vicinity of their conjugates at only Oulu $(L=4.4)$ and Rovalemi $(L=4.9)$. As previously mentioned, the conjugate effect will verified more at both Oulu and Rovalemi in the Northern conjugate. Due to an increase in data points, a linear interpolation technique is employed (Fang et al. 2007). Due to the interpolation, however, the time differences between the satellite crossings, and the coarse grid averaging out of a possible local effect, we can only expect a relative correlation between riometer measurements at these regions and the fluxes retrieved from the NOAA satellites.
Figures $5 \mathrm{a}-\mathrm{d}$ presents the electron fluxes in energy channels $>30,>100$, and $>300 \mathrm{keV}$ above Halley, SANAE IV and at the vicinity of the Northern conjugate, Oulu and Rovalemi, using simple interpolation techniques. We find that over Halley and SANAE IV, as presented in Figs. 5a and b respectively, absorption peaks coincided with relative increase in precipitating electron flux on the arrival of MC. The MC driven precipitation is seen to be energy dependent at all local times, which did not recover quickly to the pre-event level. The prolonged recovery across all the energy bands was likely to be that acceleration processes are either enhanced or dominated by multiple loss processes capable of acting on varying electron energies. This partly explains the reason for absorption peaks seen days after the event. The region near Oulu and Rovalemi in Figs. 5c and d respectively show a similar scenario for the conjugate vicinity in the Northern Hemisphere indicating, perhaps, a global feature. We find this assumption meaningful because Halley, SANAE IV and the Finnish riometer chain along the same $L$-shell are separated by about 4 hours of magnetic local time; but, at the same time we find an increase in absorption from particle precipitation at Southern Hemisphere stations to have been simultaneous to or tied with that at the Northern conjugate. The idea that this may indeed occur is a concept of simultaneous precipitation, where particles are precipitated over a wide enough region to be detected at both stations simultaneously. As seen in Fig. 3, there is a very similar absorption profile at the Halley, SANAE IV and Finnish riometers indicating that the same precipitation event was measured at both stations. Apparently, the smooth rotation of IMF-Bz converts closed electron drift paths to open paths allowing electrons to be lost through magnetopause shadowing, thus, precipitate into the mesosphere region as indicated by riometer. Similar to the modeled background electron number density in the presence of the MC-triggered absorption, we investigated the density height profile by re- placing the absorption with these 
measured differential electron fluxes as presented in Fig. 6. We find a significant correlation between Figs. 4 and 6 for densities upon a MC arrival. The high densities of electrons during the $\mathrm{MC}$ allow us to test whether a MC is related to the density of free electrons or to something else. The number density of electrons during the main phase of the event increase for both height profiles of electron density obtained from absorption and precipitating electron fluxes. The situation is obviously the same for protons as shown in Fig. 7. We find that protons across the energy channels are associated with the absorption due to the MC triggered storm.

\subsection{Energy Deposition}

Figure 8 shows the energy deposition by the electrons at the vicinity of SANAE IV and its conjugate using the MCETM discussed in Subsection 2.2.1. In Fig. 8 (top panel left), we find a local maxima of energy deposition at $90 \mathrm{~km}$ on 8 November 2004 after the impact of a MC. This is obvious from the mean profile in the top panel (right) of Fig. 8. The enhancement in the energy deposition persists till a day after the event. While we continue to notice a peak in the energy deposition, even in the Northern vicinity, Fig. 8 (bottom) shows that the situation is only comparable at $100 \mathrm{~km}$ a day after the impact of a MC. This also coincides with enhanced magnetospheric activity. Comparing the electrons deposition with the deposition by $\mathrm{MC}$ protons as presented in Fig. 9, we find that the energy deposition is generally dominated by electrons, indicating an enhanced electron fluxes.

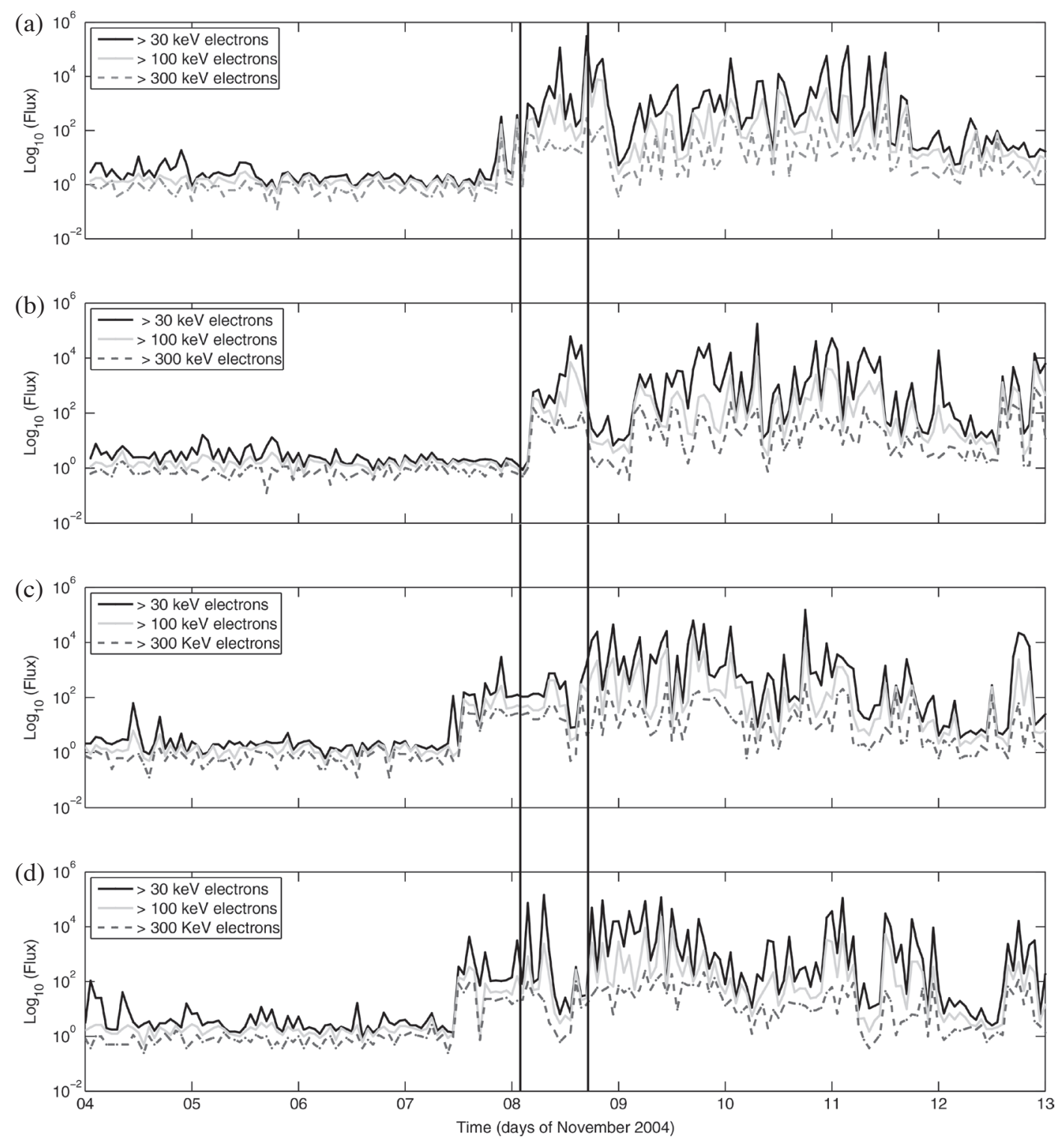

Fig. 5. NOAA/POES electrons precipitation on arrival of MC. (a - d) Indicate electron precipitation from Halley (a), SANAE IV (b), Oulu (c) and Rovalemi (d). MC interval is bordered by vertical lines. 


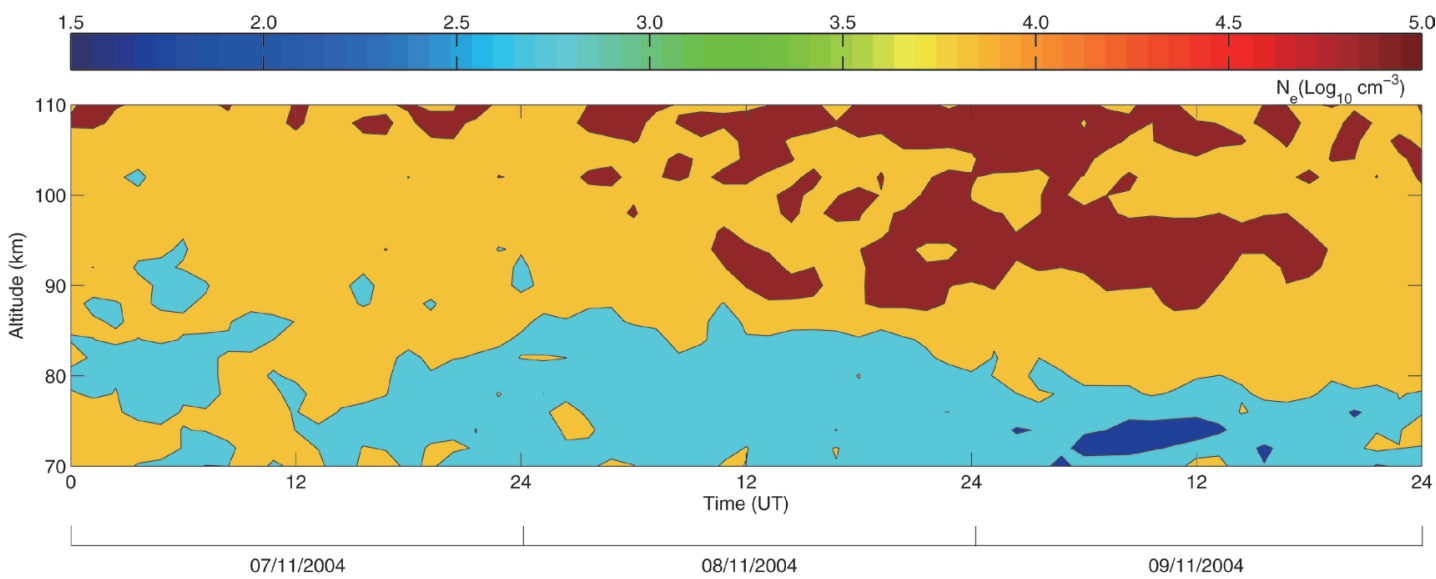

Fig. 6. Altitude-time-color map of modeled electron number density from differential electron fluxes.

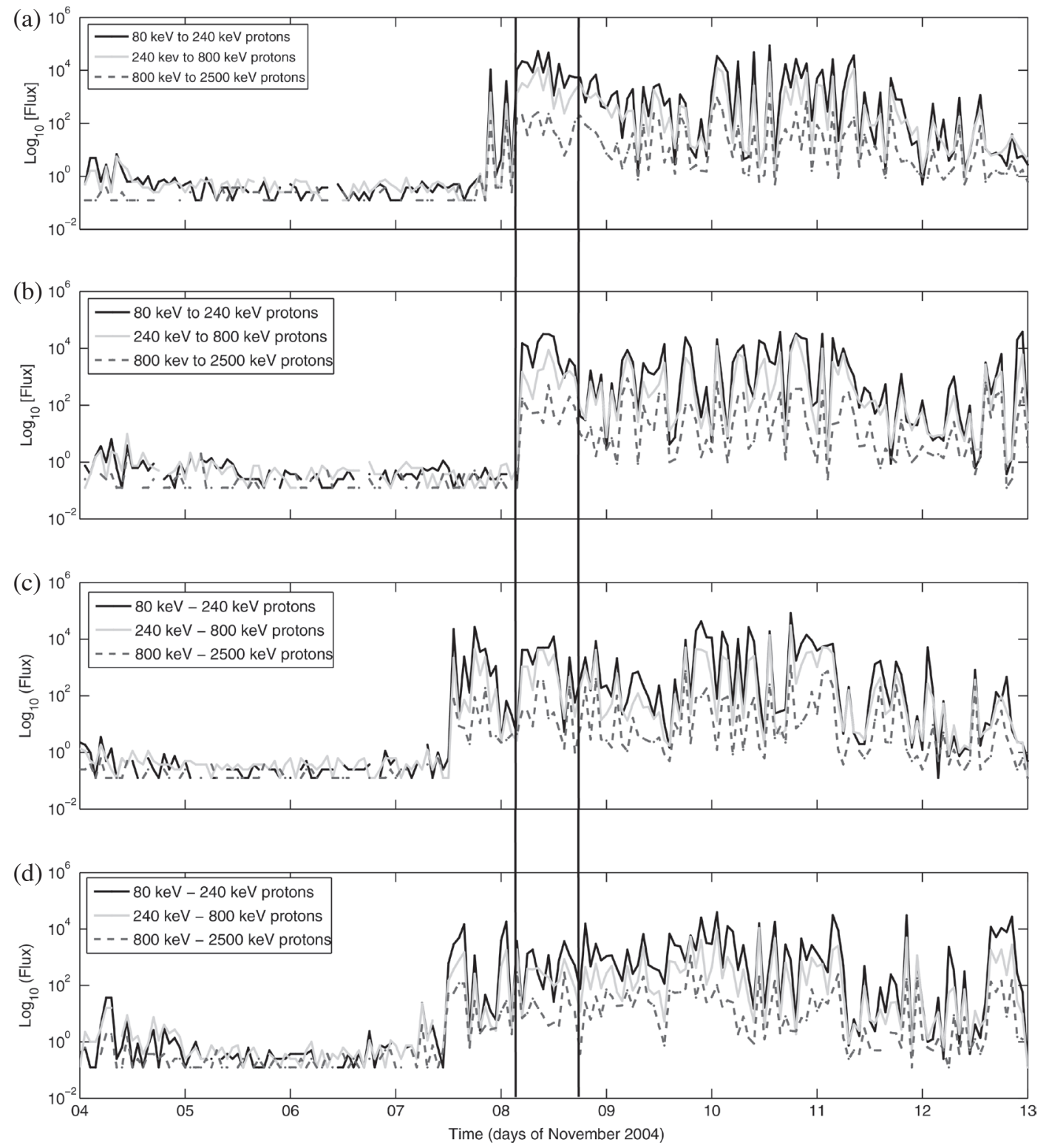

Fig. 7. NOAA/POES protons precipitation on arrival of MC. (a - d) Indicate precipitation from Halley (a), SANAE IV (b), Oulu (c) and Rovalemi (d). Format is as in Fig. 5. 

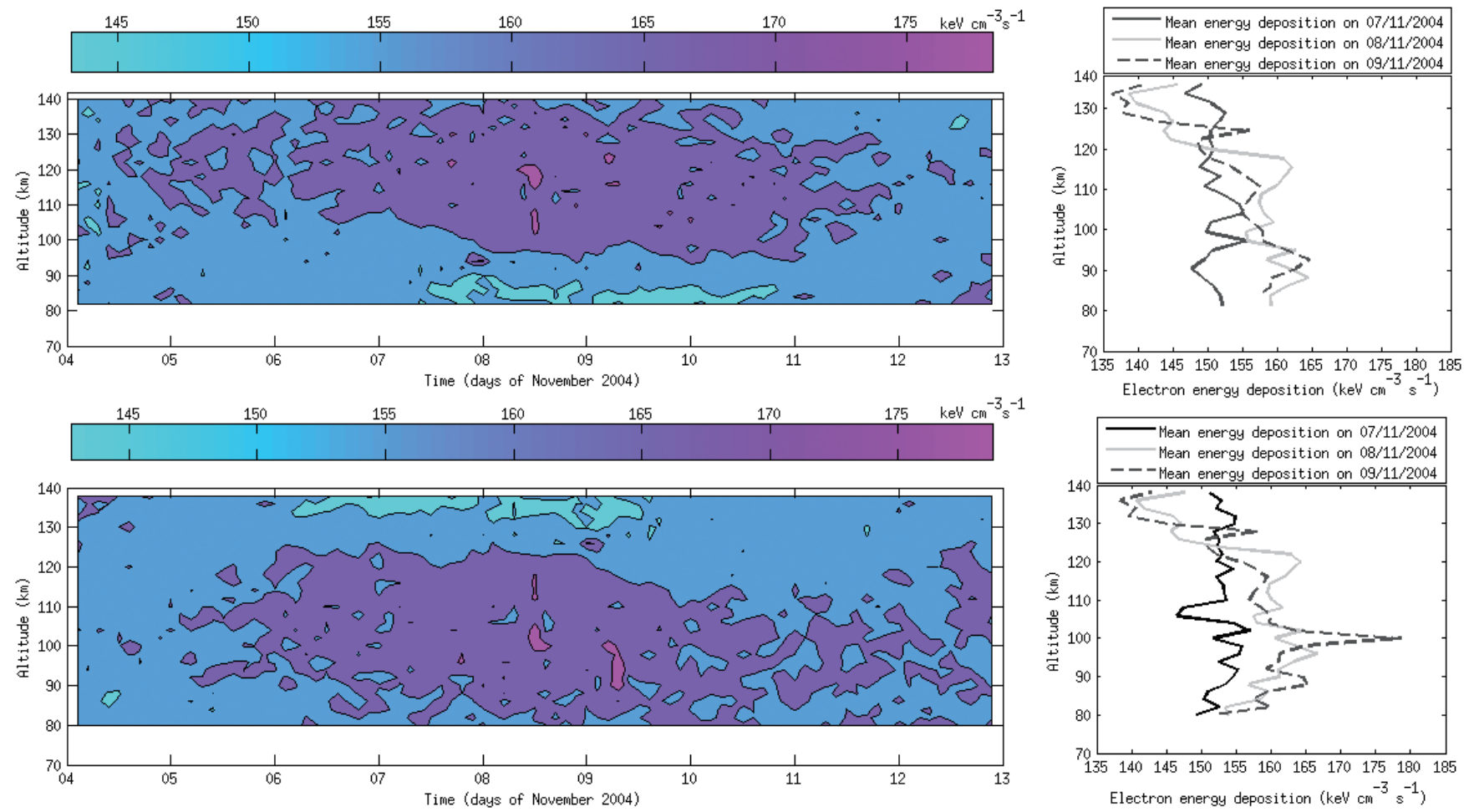

Fig. 8. Energy deposition by MC electrons. The top panel (left) shows the energy distribution as a function of altitude and time in days near SANAE IV and (right) daily mean profile centered a day on MC arrival at Earth. The bottom (left) and (right) panels are similar scenarios near Oulu in Northern Hemisphere.
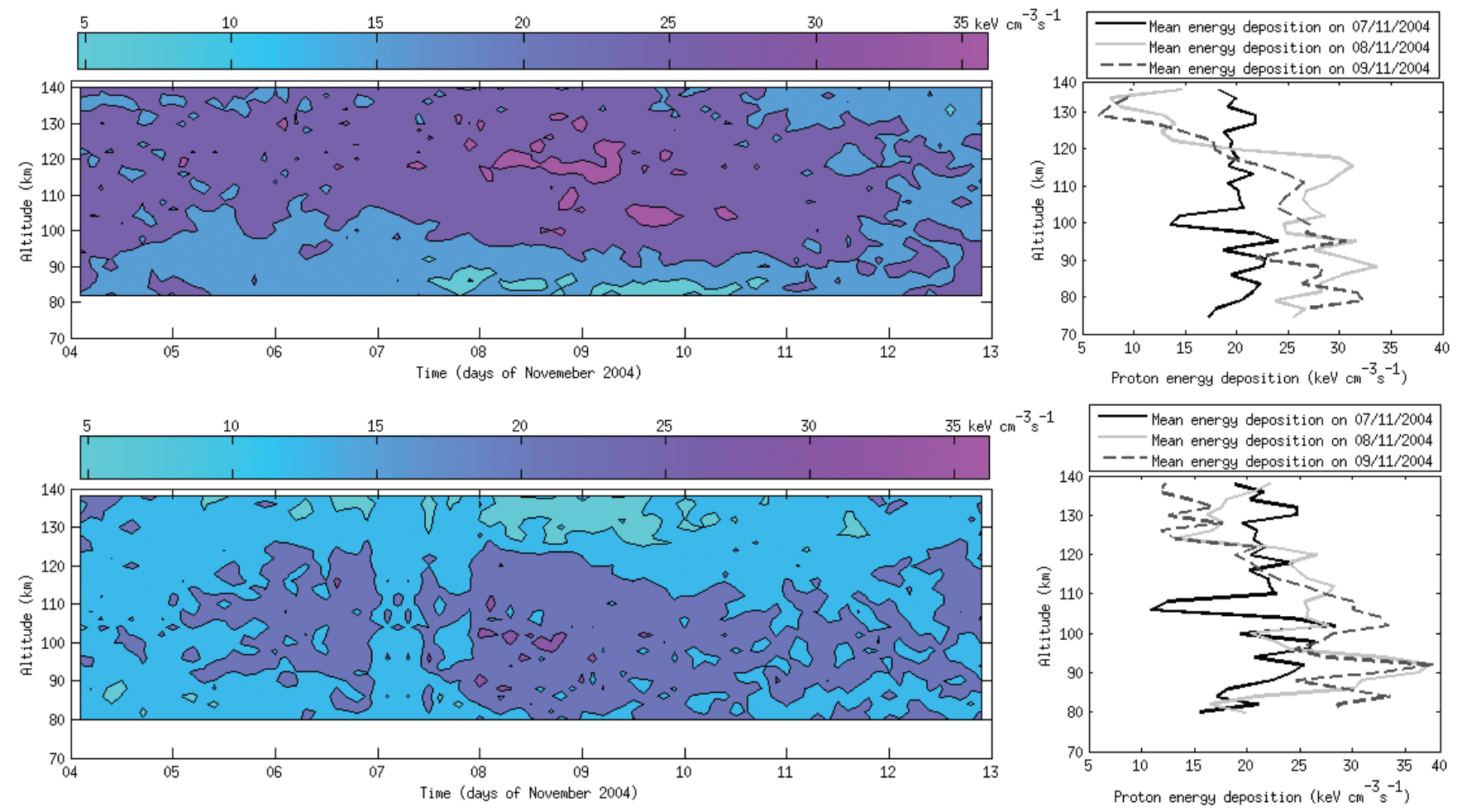

Fig. 9. Energy deposition by MC protons. Format is as in Fig. 8. 
According to Fig. 8, we find an electron energy deposition rate of about $165 \mathrm{keV} \mathrm{cm}^{-3} \mathrm{~s}^{-1}$, an equivalent of $2.64 \times 10^{-14} \mathrm{~J} \mathrm{~cm}^{-3} \mathrm{~s}^{-1}$ in an acceptable SI unit, which is $0.32 \times 10^{-14} \mathrm{~J} \mathrm{~cm}^{-3} \mathrm{~s}^{-1}$ less than what is found at $100 \mathrm{~km}$ altitude in the northern conjugate vicinity on the impact of $\mathrm{MC}$. This is capable of giving rise to a heating rate of approximately $0.77 \mathrm{~K} \mathrm{~h}^{-1}$ in an ideal diatomic gas atmosphere or about $0.12 \mathrm{~K} \mathrm{~h}^{-1}$ if the atmosphere is assumed to be ideal monoatomic at this altitude. The rate derived for diatomic gas atmosphere is in close agreement with previous work posted by Offermann (1985), who found particle precipitation heating rates of approximately $0.1 \mathrm{~K} \mathrm{~h}^{-1}$ at $90 \mathrm{~km}$ during high geomagnetic conditions which is in closer agreement to what we have obtained for our region of interest in Northern hemisphere and at its conjugate. Energetic particles can cause heating and eventual cooling, depending upon which altitude is studied and the specific militating condition. Here, we find that energy deposition is deeper in the Southern hemisphere than in the Northern conjugate upon the arrival of a MC.

But it is more likely, however, that the arrival of MC causes the persistence of energy deposition seen days after the event. This is arguable since this paper presents a case study. However, momentum flux, that is, correlation of the meridional $(\mathrm{V})$ winds and the longitudinal asymmetry of the zonal (U) wind, is a good proxy for disturbed mesopause region from geoineffective sources. Futurology aims to investigate momentum flux using neutral wind measurements from SuperDARN radar network. With this, we would be able to quantify the character of global-scale meridional wave period. A visual check on the QBO upon arrival of this left-handed MC shows that it was during easterly phase, indicating a probable disturbed stratosphere (Georgieva et al. 2005) caused by this event.

\section{SUMMARY AND CONCLUSIONS}

The MC event which occurred on 8 November 2004 coincided with enhanced magnetospheric conditions. On the arrival of the MC at Earth, which triggered large geomagnetic disturbance, we estimated energy deposition into the atmosphere. Upon arrival, the Halley riometers in Antarctica and that of Finish, a conjugate vicinity in the opposite hemisphere, indicated absorption peaks and enhanced electron densities. The energy deposited at this time interacted with various plasma waves and thus, causing enhanced ionospheric density within collision dominated regions. The electron number density calculations show enhanced densities above $90 \mathrm{~km}$ on the impact of MC which coincides with the rise in magnetospheric convection. Energetic particle measurements from NOOA/POES that pass through and near these regions confirm that the absorption events are most likely due to particle precipitation caused by the arrival of MC. Using MCETM shows that the energy deposition dominated by electrons on arrival of this event is capable of giving rise to an heating rate of approximately $0.77 \mathrm{~K} \mathrm{~h}^{-1}$ in an ideal diatomic gas atmosphere or about $0.12 \mathrm{~K} \mathrm{~h}^{-1}$ if the atmosphere is assumed to be ideal monoatomic at the altitude of about $100 \mathrm{~km}$, which is in close agreement to previous work in the Northern Hemisphere. It was found that an approximation of these energy deposition rates for Southern Hemisphere extends to lower altitudes. Considering the size of the estimated heating rates, it could be hypothesized that there is significant temperature effects on the particle precipitation in the upper mesosphere above these regions following the arrival of MC. We choose to be prudent with our conclusions regarding these solar influences however, since the magnitude of the heating and cooling rate associated with MC do not necessarily preclude influences by atmospheric features such as tides and gravity waves as these remain an arduous challenge. In order to elucidate what these effects might have, further work is underway to analyze the associated wave field with the MC arrival at Earth. The particle precipitation investigated in the present study occurred during ICME-driven storms. Precipitation also needs to be studied in high-speed-solar wind-driven storms. Because high-speed-solar wind-driven storms are more variable than the ICME-driven storms, the rate of energy deposition under more varied conditions will be studied.

Acknowledgements The authors are grateful for the availability of OMNI data provided by the GSFC/SPDF at the OMNIWeb interface, the NOAA/POES at NGDC and Finnish chain of riometers in SGO. The SuperDARN radar network and Halley riometer data are provided by the British Antarctic Survey, UK, from their Web site at http://psddb. nerc-bas.ac.uk/. And, the authors also express thanks to TAO's anonymous reviewers for their valuable comments and suggestions. Research is supported by the South African National Space Agency (SANSA).

\section{REFERENCES}

Antonucci, E., J. T. Hoeksema, and P. H. Scherrer, 1990: Rotation of the photospheric magnetic fields: A northsouth asymmetry. Astrophys. J., 360, 296-304, doi: 10.1086/169120. [Link]

Berger, M. J., S. M. Seltzer, and K. Maeda, 1970: Energy deposition by auroral electrons in the atmosphere. $J$. Atmos. Terr. Phys., 32, 1015-1045, doi: 10.1016/00219169(70)90115-7. [Link]

Browne, S., J. K. Hargreaves, and B. Honary, 1995: An imaging riometer for ionospheric studies. Electron. Comm. Eng. J., 7, 209-217, doi: 10.1049/ecej:19950505. [Link]

Burlaga, L. F., 1988: Magnetic clouds and force-free fields with constant alpha. J. Geophys. Res., 93, 7217-7224, doi: 10.1029/JA093iA07p07217. [Link]

Burlaga, L. F., L. Klein, N. R. Sheeley Jr., D. J. Michels, 
R. A. Howard, M. J. Koomen, R. Schwenn, and H. Rosenbauer, 1982: A magnetic cloud and a coronal mass ejection. Geophys. Res. Lett., 9, 1317-1320, doi: 10.1029/GL009i012p01317. [Link]

Clilverd, M. A., C. J. Rodger, R. J. Gamble, T. Ulich, T. Raita, A. Seppälä, J. C. Green, N. R. Thomson, J. A. Sauvaud, and M. Parrot, 2010: Ground-based estimates of outer radiation belt energetic electron precipitation fluxes into the atmosphere. J. Geophys. Res., 115, A12304, doi: 10.1029/2010JA015638. [Link]

Estep, G. M., J. L. Horwitz, Y. J. Su, P. G. Richards, G. R. Wilson, and D. G. Brown, 1999: A Dynamic FluidKinetic (DyFK) model for ionosphere-magnetosphere plasma transport: Effects of ionization and thermal electron heating by soft electron precipitation. Terr. Atmos. Ocean. Sci., 10, 491-510.

Fang, X., M. W. Liemohn, J. U. Kozyra, D. S. Evans, A. D. DeJong, and B. A. Emery, 2007: Global 30-240 $\mathrm{keV}$ proton precipitation in the 17-18 April 2002 geomagnetic storms: 1. Patterns. J. Geophys. Res., 112, A05301, doi: 10.1029/2006JA011867. [Link]

Georgieva, K.,B.Kirov, D. Atanassov, and A. Boneva, 2005: Impact of magnetic clouds on the middle atmosphere and geomagnetic disturbances. J. Atmos. Sol.-Terr. Phys., 67, 163-176, doi: 10.1016/j.jastp.2004.07.025. [Link]

Grenfell, J. L., R. Lehmann, P. Mieth, U. Langematz, and B. Steil, 2006: Chemical reaction pathways affecting stratospheric and mesospheric ozone. J. Geophys. Res., 111, D17311, doi: 10.1029/2004JD005713. [Link]

Hargreaves, J. K., 1969: Auroral absorption of HF radio waves in the ionosphere: A review of results from the first decade of riometry. $P$. IEEE., 57, 1348-1373, doi: 10.1109/PROC.1969.7275. [Link]

Hargreaves, J. K., 1992: The Solar-Terrestrial Environment: An Introduction to Geospace - the Science of the Terrestrial Upper Atmosphere, Ionosphere, and Magnetosphere, Cambridge Atmospheric and Space Science Series, Cambridge University Press, Cambridge, 420 pp.

Hargreaves, J. K. and M. Friedrich, 2003: The estimation of D-region electron densities from riometer data. Ann. Geophys., 21, 603-613, doi: 10.5194/angeo-21-603-2003. [Link]

Hviuzova, T. and S. Leontyev, 1997: Characteristics of aurora spectra connected with high-speed streams from coronal holes. Geomagn. Aeron., 37, 155-159. (in Russia)

Hviuzova, T. and S. Leontyev, 2001: Characteristics of aurora spectra connected with non-stationary solar wind streams. Geom. Aeron., 41, 337-341. (in Russia)

Kang, J. E., S. K. Song, H. W. Lee, and Y. K. Kim, 2012: The influence of meteorological conditions and complex topography on ozone concentrations in a valley area near coastal metropolitan cities. Terr. Atmos. Ocean. Sci., 23, 25-38, doi: 10.3319/TAO.2011.06.30.02(A). [Link]
King, J. H. and N. E. Papitashvili, 2005: Solar wind spatial scales in and comparisons of hourly wind and ace plasma and magnetic field data. J. Geophys. Res., 110, A02104, doi: 10.1029/2004JA010649. [Link]

Lam, M. M., R. B. Horne, N. P. Meredith, S. A. Glauert, T. Moffat-Griffin, and J. C. Green, 2010: Origin of energetic electron precipitation $>30 \mathrm{keV}$ into the atmosphere. J. Geophys. Res., 115, A00F08, doi: 10.1029/2009JA014619. [Link]

Lepping, R. P., J. A. Jones, and L. F. Burlaga, 1990: Magnetic field structure of interplanetary magnetic clouds at 1 AU. J. Geophys. Res. 95, 11957-11965, doi: 10.1029/ JA095iA08p11957. [Link]

Lepping, R. P., L. F. Burlaga, A. Szabo, K. W. Ogilvie, W. H. Mish, D. Vassiliadis, A. J. Lazarus, J. T. Steinberg, C. J. Farrugia, L. Janoo, and F. Mariani, 1997: The wind magnetic cloud and events of october 18 - 20, 1995: Interplanetary properties and as triggers for geomagnetic activity. J. Geophys. Res., 102, 14049-14063, doi: 10.1029/97JA00272. [Link]

Mæhlum, B. N., 1973: Particle precipitation: Scattering and absorption. In: Egeland, A., Ø. Holter, and A. Omholt (Eds.), Cosmical Geophysics, Universitetsforlaget, 211-219.

Majumdar, R. C., 1972: Generalization of appleton-hartree equation of theories of collision frequency. Indian $J$. Radio Space, 1, 31-37.

Offermann, D., 1985: The energy budget campaign 1980: Introductory review. J. Atmos. Terr. Phys., 47, 1-26, doi: 10.1016/0021-9169(85)90120-5. [Link]

Rees, M. H., 1989: The interaction of energetic solar photons with the upper atmosphere. Physics and Chemistry of the Upper Atmosphere, Cambridge Atmospheric and Space Science Series, Cambridge University Press, Cambridge, 8-23, doi: 10.1017/ CBO9780511573118.003. [Link]

Roble, R. G., 1995: Energetics of the mesosphere and thermosphere, in The Upper Mesosphere and Lower Thermosphere: A Review of Experiment and Theory. AGU, Washington D.C., 87, 1-21.

Rodger, C. J., M. A. Clilverd, J. C. Green, and M. M. Lam, 2010a: Use of POES SEM-2 observations to examine radiation belt dynamics and energetic electron precipitation into the atmosphere. J. Geophys. Res., 115, A04202, doi: 10.1029/2008JA014023. [Link]

Rodger, C. J., M. A. Clilverd, A. Seppälä, N. R. Thomson, R. J. Gamble, M. Parrot, J. A. Sauvaud, and T. Ulich, 2010b: Radiation belt electron precipitation due to geomagnetic storms: Significance to middle atmosphere ozone chemistry. J. Geophys. Res., 115, A11320, doi: 10.1029/2010JA015599. [Link]

Roederer, J. G., 1970: Dynamics of Geomagnetically Trapped Radiation, Physics and Chemistry in Space, vol. 2, Springer-Verlag, New York, 166 pp. 
Rusch, D. W., J. C. Gérard, S. Solomon, P. J. Crutzen, and G. C. Reid, 1981: The effect of particle precipitation events on the neutral and ion chemistry of the middle atmosphere-I. odd nitrogen. Planet. Space Sci., 29, 767-774, doi: 10.1016/0032-0633(81)90048-9. [Link]

Sætre, C., J. Stadsnes, H. Nesse, A. Aksnes, S. M. Petrinec, C. A. Barth, D. N. Baker, R. R. Vondrak, and N. Østgaard, 2004: Energetic electron precipitation and the NO abundance in the upper atmosphere: A direct comparison during a geomagnetic storm. J. Geophys. Res., 109, A09302, doi: 10.1029/2004JA010485. [Link]

Sivjee, G. G. and D. Shen, 1997: Auroral optical emissions during the solar magnetic cloud event of October 1995. J. Geophys. Res., 102, 7431-7437, doi: 10.1029/97JA00195. [Link]

Solomon, S., D. W. Rusch, J. C. Gérard, G. C. Reid, and P. J. Crutzen, 1981: The effect of particle precipitation events on the neutral and ion chemistry of the middle atmosphere: II. Odd hydrogen. Planet. Space Sci., 29, 885-893, doi: 10.1016/0032-0633(81)90078-7. [Link]

Sripathi, S., 2012: COSMIC observations of ionospheric density profiles over Indian region: Ionospheric conditions during extremely low solar activity period. Indian J. Radio Space Phys., 41, 98-109.
Swider, W. and T. J. Keneshea, 1973: Decrease of ozone and atomic oxygen in the lower mesosphere during a PCA event. Planet. Space Sci., 21, 1969-1973, doi: 10.1016/0032-0633(73)90126-8. [Link]

Wang, Y.M.,P.Z. Ye, and S. Wang, 2003: Multiple magnetic clouds: Several examples during March-April 2001. J. Geophys. Res., 108, doi: 10.1029/2003JA009850. [Link]

Wang, Z., T. J. Rosenberg, P. Stauning, S. Basu, and G. Crowley, 1994: Calculations of riometer absorption associated with $F$ region plasma structures based on Sondre Stromfjord incoherent scatter radar observations. Radio Sci., 29, 209-215, doi: 10.1029/93RS01507. [Link]

Wilson, A. and P. H. Stoker, 2002: Imaging riometer observations on energetic electron precipitation at SANAE IV, Antarctica. J. Geophys. Res., 107, doi: 10.1029/2000JA000463. [Link]

Zhang, J., M. W. Liemohn, J. U. Kozyra, M. F. Thomsen, H. A. Elliott, and J. M. Weygand, 2006: A statistical comparison of solar wind sources of moderate and intense geomagnetic storms at solar minimum and maximum. J. Geophys. Res., 111, A01104, doi: 10.1029/2005JA011065. [Link] 